\title{
The relationship of illicit drug use to HIV-infection among commercial sex workers in the city of Santos, São Paulo, Brazil
}

\author{
Celia L. Szwarcwald ${ }^{\mathrm{a}, *}$, Francisco I. Bastos ${ }^{\text {a }}$, Neide Gravato ${ }^{\mathrm{b}, \mathrm{c}}$, Regina Lacerda ${ }^{\mathrm{b}, \mathrm{c}}$, \\ Pedro N. Chequer ${ }^{d}$, Euclides A. de Castilho ${ }^{d}$ \\ a Department of Information on Health, Oswaldo Cruz Foundation, Av. Brazil 4365 RJ, 21045-900 Rio de Janeiro, Brazil \\ b Municipal Health Secretariat, Santos, SP, Brazil \\ c Association for Research, Prevention and Education on STDs/AIDS of Santos, Santos, SP, Brazil \\ ${ }^{\mathrm{d}}$ Brazilian Ministry of Health, Brasilia, DF, Brazil
}

Received 15 April 1998; received in revised form 24 September 1998; accepted 24 September 1998

\begin{abstract}
Objective: To assess the role of illicit drug use as a risk factor of HIV infection among female commercial sex workers (CSWs) in the city of Santos, Brazil. Design: Cross-sectional survey of 697 chain-referred CSWs. Methodology: The study included information on social-demographic characteristics, sexual practices and use of illicit drugs. Blood samples were tested for HIV. Associations between the response variable and drug-related variables, controlling for potential confounders, were assessed through multiple logistic regression procedures. Results: The univariate analyses for all drug-related variables evidenced that 'use of injecting drugs' (odds-ratios $(\mathrm{OR})=10.9)$ and 'use of crack in the previous month' $(\mathrm{OR}=9.0)$, were the two variables most highly associated to the outcome. The multivariate analysis emphasized the role of crack use, the first variable included in the stepwise procedure (adjusted $\mathrm{OR}=5.3, P=0.0001)$. Other relevant predictors were 'educational level' $(P=0.0003)$, 'practice of anal intercourse with customers' $(P=0.0031)$, 'use of injecting drugs' (adjusted $\mathrm{OR}=3.1, P=0.0647)$, 'age at first intercourse' $(P=0.0188)$ and 'age' $(P=0.0175)$. Additional multivariate results showed that crack-users tend to use other drugs simultaneously, to agree more frequently to have unprotected sex and to earn a significantly smaller payment per sexual encounter than crack non-users. Conclusions: The analysis showed the vulnerability of CSWs in relation to drug use, lack of education and unprotected sex. These findings highlight the need for preventive programs focused on the general use of drugs in this population as well as efforts to help CSWs to acquire educational and professional skills. C) 1998 Elsevier Science B.V. All rights reserved.
\end{abstract}

Keywords: Crack cocaine; AIDS; HIV; Commercial sex workers; Brazil

* Corresponding author. Fax: + 5521 2901696; e-mail: celia@malaria.procc.fiocruz.br 


\section{Introduction}

In studies of epidemics secondary to direct and intimate contact, as is the case of sexually transmissible epidemics, it is important to consider the role of specific population segments at special risk (core groups) and of great social interaction (Woodhouse et al., 1994). Female commercial sex workers (CSWs) are among such core groups in many settings, especially in developing countries (Weniger et al., 1991; Lurie et al., 1995).

In Brazil, HIV infection rates in population segments at high risk have been broadly investigated (Bastos et al., 1995). Specifically for female CSWs, a study in the State of São Paulo, including samples from the cities of São Paulo (the capital of the state), Campinas and Santos, found evidence of very high HIV infection rates, mainly among women with low socioeconomic status. In particular, the highest HIV infection rate $(27 \%)$ has been found in the poorest stratum (Lurie et al., 1995).

Previous investigations in the city of Santos, the main seaport of Latin America and an important tourist center, pointed to high levels of risk behaviors, but, so far, moderate levels of HIV infection (1-2\%) among different populations, e.g. port workers (Lacerda et al., 1996), or among the numerous truck drivers that arrive daily in the city from diverse parts of South America (Lacerda et al., 1997). Higher levels of HIV seroprevalence (3-4\%) were found in previous surveys carried out in different groups of pregnant women (Porto et al., 1992, 1996).

The 'feminization' of the AIDS epidemic in Santos has been very precocious if compared to the Brazilian HIV/AIDS epidemic as a whole. The current Brazilian AIDS cases sex ratio (1:3 female/male) was reached in Santos 7 years before (Porto et al., 1992), which emphasizes the pressing need to implement prevention programs among women.

A former study carried out among CSWs of Santos found very high levels of infection for different STDs. For 45 female CSWs, who reported at least five partners a day, prevalence rates of $29 \%$ were found for syphilis (Treponema sp.), $43 \%$ for hepatitis B and $100 \%$ for Chlamydia trachomatis (Caterino-de-Araújo and Fortuna, 1990).

Moreover, the city of Santos has reported the highest AIDS incidence rate among all municipalities in Brazil for 8 subsequent years. Nowadays, it is ranked among the three topmost municipalities (Brazilian Ministry of Health, 1997) and shows one of the highest absolute numbers and relative frequency of injecting drug users (IDU) among reported AIDS cases.

From 1990 on, a significant increase in crack use has been observed in several cities of the State of São Paulo, specifically in the region named 'Baixada Santista', which incorporates the city of Santos and other tourist cities nearby. On the other hand, studies carried out both in Brazil (Bueno et al., 1992) and Europe (Alary et al., 1994) have shown that female CSWs who inject drugs (or who use drugs in general) have significantly higher HIV infection rates than non-users. The objective of the present investigation is to assess the role of illicit drug use as a risk factor of HIV infection among female CSWs in the city of Santos. We analyzed data on cocaine use, whether snorted, smoked (crack cocaine) or injected, as well as other illicit drug use collected in a study of female CSWs carried out in the city of Santos in 1996.

\section{Subjects and methods}

\subsection{The sample and HIV testing procedures}

Since 1994, a trained group of health professionals has been conducting a preventive program among female CSWs in the Municipality of Santos. During this period, 52 prostitution areas have been visited weekly. The program includes educational activities, counseling, medical assistance, referral and condom distribution.

As part of the program, in 1996, a sample of 697 chain-referred CSWs was selected for epidemiological investigation. The sample size was calculated to estimate the HIV infection rate within a 95\% confidence interval no wider than $4 \%$, based on the supposition of a prevalence rate of $7.5 \%$. Both street ( $25 \%$ of the total sample) and 
indoor CSWs (nightclubs, bars, hotels, etc.) were recruited. Efforts to select a representative sample of CSWs from Santos included the use of a mobile health unit. Several prostitution areas were visited at different times during the day and night. The study included an interview as well as screening for HIV infection and other STDs.

Demographic, socioeconomic and behavioral data, as well as blood samples, were collected from the sampled women by health professionals (three psychologists and one social worker) from a non-Government organization - the Association for Research, Prevention and Education on STDs/AIDS of Santos - in consortium with the Health Secretariat of Santos, after signing the informed consent term. Interviews were administered in the downtown Municipal Health Center in a private room or inside the mobile unit (a van), always in a private setting: the interviewer and the interviewee.

Given the characteristics of the term of consent (in accordance with the Santos' Faculty of Medicine IRB norms), only women aged 18 and over were included in the survey. HIV infection was detected by means of two enzyme-linked immunoabsorbent assays (Elisa; Organon Teknoka, Boxtei, the Netherlands). All ELISA positive samples were confirmed using the Western blot immune assay on strips (Sanofi-Pasteur, Paris, France).

\subsection{The questionnaire}

The questionnaire included information on individual characteristics, on living standards, on their activity, on sexual practices with customers and regular partners and on frequency of condom use.

Part of the questionnaire was specifically dedicated to gather information on drug use. Questions included frequency of use of illicit drugs such as marijuana, powder cocaine, glue, amphetamines, crack and LSD, in the last month before the interview. Further questions involved use of injected drugs (basically cocaine powder) by the CSWs themselves, their customers and regular partners.

\subsection{Analytic plan}

For this particular study, only a few variables have been selected for analysis: 'age'; 'age at first intercourse'; 'cash amount for the last sexual encounter' (refers to any sexual activity with a customer); 'educational level'; 'Do you have anal intercourse with customers?'; 'Do you agree not to use condoms if you need cash?'; 'Did you smoke marijuana in the previous month?'; 'Did you snort cocaine in the previous month?'; 'Did you use crack in the previous month?'; 'Have you ever injected drugs?'; 'Do you know if your partner is (or has been) an IDU?'; 'Do you accept IDU customers?'. Due to the very small number of women that shared use of injecting equipment (eight CSWs), this variable could not be included in the analysis.

In the first part of the statistical analysis, the association between each categorical variable and HIV infection was assessed by estimating individual odds-ratios (OR) and 95\% confidence intervals (Bishop et al., 1975). Similarly, for each continuous variable, the association was assessed by estimating the exponential of the corresponding coefficient of the univariate logistic regression $(\exp (\beta))$.

Due to the irrelevant differences between the OR for incomplete and complete primary schooling (data not shown), educational level was dichotomized as illiterate (no reading skills) and other.

To establish the most highly correlated drug-related variable to HIV infection, a multivariate analysis was performed. All variables relative to use of illicit drugs composed the set of independent variables in a multiple logistic regression analysis. A stepwise procedure was used, maximizing at each step the likelihood ratio. The significance level for variable inclusion was 5 and $10 \%$, the significance level for exclusion (Hosmer and Lemeshow, 1989).

Additionally, to assess the role of illicit drug use as a risk factor of HIV infection, adjusting for the other variables considered in the study, we analyzed all variables together in a multivariate form. That is, the drug-related variables and the other independent variables (taken as potential 
confounders) were considered altogether in a multiple logistic regression model. Again, a stepwise procedure was used (as described before), and the 'best' model provided the adjusted OR (Kahn and Sempos, 1989).

Finally, to provide a better understanding of the relationship of crack use to HIV infection, we attempted to characterize the crack using CSWs. A multiple logistic regression was used to establish differences between the crack users and crack non-users.

\section{Results}

\subsection{Demographic characteristics and patterns of drug consumption}

Descriptive statistics for all variables considered in the study are presented in Table 1. Of the 697 female CSWs, 58 (8.3\%) were HIV-positive. The sampled women showed very low educational level, as $6.5 \%$ were illiterate (almost all of them work in the streets) and $57 \%$ had incomplete primary schooling (street and indoor CSWs). In relation to age, the majority were young $(60 \%$ were $<29$ years old), although the age range was wide, from 18 to 65 years old. The mean for 'age at first intercourse' was $\approx 15$ years, very close to the median and the mode. Regarding 'cash amount for last sexual encounter', values range from the equivalent of US\$5-900, the median was US\$50.00 and the 90th percentile was equal to US\$140.00. It is interesting to note that this variable showed three very frequent values (US\$20.00; 50.00 and 100.00), probably reflecting the wide contextual differences in CSWs settings. As to sexual practices, nearly $20 \%$ of the women had anal intercourse with customers and in respect to the use of condoms, $13 \%$ agreed to have unprotected intercourse if in need of money.

Characteristics relative to illicit-drug use are also shown in Table 1. The reported proportion of use was quite high: $16 \%$ of the female CSWs used marijuana, 13\% snorted cocaine and 6.6\% smoked crack at least once in the previous 30 days. Although the proportion of CSWs who used snorted cocaine was more than twice the propor-
Table 1

Descriptive statistics for all considered variables

\begin{tabular}{|c|c|}
\hline Variables & Statistics \\
\hline \multicolumn{2}{|l|}{ HIV-infection } \\
\hline Yes $(\%)$ & 8.5 \\
\hline \multicolumn{2}{|l|}{ Age } \\
\hline Mean \pm S.D. & $27.4 \pm 8.4$ \\
\hline Median & 25.0 \\
\hline Range & $18-65$ \\
\hline 90th Percentile & 39.0 \\
\hline \multicolumn{2}{|l|}{ Age at first intercourse } \\
\hline Mean \pm S.D. & $15.4 \pm 2.6$ \\
\hline Median & 15.0 \\
\hline Range & $6-29$ \\
\hline 90th Percentile & 18.0 \\
\hline \multicolumn{2}{|l|}{$\begin{array}{l}\text { Cash amount for last sexual encounter } \\
\text { (US\$) }\end{array}$} \\
\hline Mean \pm S.D. & $68.1 \pm 80.8$ \\
\hline Median & 50.0 \\
\hline Range & $5-900$ \\
\hline 90th Percentile & 140.0 \\
\hline \multicolumn{2}{|l|}{ Educational level } \\
\hline $\begin{array}{l}\text { Illiterate }(\%) \text {; incomplete primary } \\
\text { schooling }(\%) \text {; complete primary } \\
\text { schooling }(\%)\end{array}$ & $6.5 ; 57.0 ; 36.5$ \\
\hline \multicolumn{2}{|l|}{$\begin{array}{l}\text { Do you have anal intercourse with } \\
\text { customers? }\end{array}$} \\
\hline Yes $(\%)$ & 20.5 \\
\hline \multicolumn{2}{|l|}{$\begin{array}{l}\text { Do you agree not to use condoms if } \\
\text { you need cash? }\end{array}$} \\
\hline Yes $(\%)$ & 12.7 \\
\hline \multicolumn{2}{|l|}{$\begin{array}{l}\text { Did you use marijuana in the last } \\
\text { month? How many times? }\end{array}$} \\
\hline Yes $(\%)$ & 16.5 \\
\hline Mean \pm S.D. & $15.2 \pm 17.4$ \\
\hline Median & 5.0 \\
\hline Range & $1-90$ \\
\hline 90th Percentile & 30.0 \\
\hline \multicolumn{2}{|l|}{$\begin{array}{l}\text { Did you snort cocaine in the last } \\
\text { month? How many times? }\end{array}$} \\
\hline Yes $(\%)$ & 13.5 \\
\hline Mean \pm S.D. & $6.4 \pm 8.7$ \\
\hline Median & 3.0 \\
\hline Range & $1-30$ \\
\hline 90th Percentile & 22.8 \\
\hline \multicolumn{2}{|l|}{$\begin{array}{l}\text { Did you smoke crack in the last } \\
\text { month? How many times? }\end{array}$} \\
\hline Yes $(\%)$ & 6.6 \\
\hline Mean \pm S.D. & $23.2 \pm 17.5$ \\
\hline Median & 29.0 \\
\hline Range & $1-60$ \\
\hline 90th Percentile & 53.0 \\
\hline
\end{tabular}


Table 1

Descriptive statistics for all considered variables

\begin{tabular}{lc}
\hline Variables & Statistics \\
\hline $\begin{array}{l}\text { Have you ever injected drugs? } \\
\text { Yes }(\%)\end{array}$ & 3.2 \\
$\begin{array}{l}\text { Do you know if your partner is (or has } \\
\text { been) an IDU? }\end{array}$ \\
$\quad \begin{array}{l}\text { Yes (\%) } \\
\text { Do you accept IDU customers? } \\
\quad \text { Yes }(\%)\end{array}$ \\
\hline
\end{tabular}

tion of CSWs who used crack, for the latter, the use was considerably more frequent. The crack median frequency of use was equal to 29 times per month while the median frequency of use for snorted cocaine was 3 per month. As to injecting drug use, only $22(3 \%)$ injected or had injected, $10 \%$ were aware that their regular partners were (or had been) IDU and 9\% accepted IDU customers.

\subsection{HIV risk behaviors}

Associations between each of the independent variables considered in this study and the response-variable are shown in Table 2. Among the illiterate CSWs, the proportion of HIV-positive women was $29 \%$, while the proportion among those with some schooling was $7 \%(\mathrm{OR}=5.5)$. For CSWs who had anal intercourse with customers, the HIV infection rate $(14 \%)$ was twice the rate among CSWs who abstain from this practice $(7 \%)$. A significant association was also found for the question 'Do you agree not to use condoms if you need cash?' The corresponding OR was equal to 2.7. As to age, HIV positive CSWs had a higher mean (30.1 years-old) compared to the others (26.8 years-old) and earned, on average, a significantly lower payment per sexual encounter, the mean difference being $\approx$ US $\$ 40.00$. Another significant discriminating variable was 'age at first intercourse', with a lower mean value among infected CSWs (14.2 years old) than among non-infected women (15.5 years old).

Concerning the use of illicit drugs, the highest OR was found for the variable 'Have you ever

Table 2

Associations of each considered variable to HIV-infection

\begin{tabular}{|c|c|c|c|c|c|}
\hline \multirow[t]{2}{*}{ Continuous variables } & \multicolumn{2}{|l|}{ Mean } & \multirow[t]{2}{*}{$\exp (\beta)^{\mathrm{a}}$} & \multirow[t]{2}{*}{$95 \% \mathrm{CI}$} & \multirow[t]{2}{*}{$P$-value } \\
\hline & $\mathrm{HIV}+$ & HIV - & & & \\
\hline Age & 31.8 & 27.0 & 1.06 & $1.02-1.08$ & 0.0001 \\
\hline Age at first intercourse & 14.2 & 15.5 & 0.79 & $0.71-0.89$ & 0.0001 \\
\hline Cash amount for last sexual encounter & 31.2 & 71.6 & 0.97 & $0.96-0.98$ & 0.0000 \\
\hline \multirow[t]{2}{*}{ Categorical variables } & \multicolumn{2}{|c|}{ HIV-infection rate $(\%)$} & \multirow[t]{2}{*}{ OR } & \multirow[t]{2}{*}{$95 \% \mathrm{CI}$} & \multirow[t]{2}{*}{$P$-value } \\
\hline & 1 & 0 & & & \\
\hline Educational level (1-illiterate/0-others) & 28.9 & 6.9 & 5.46 & $2.68-11.13$ & 0.0000 \\
\hline Do you have anal intercourse with customers? (1-yes/0-no) & 14.1 & 6.9 & 2.21 & $1.24-3.93$ & 0.0071 \\
\hline Have you ever injected drugs? (1-yes/0-no) & 45.5 & 7.0 & 10.99 & $4.51-26.77$ & 0.0000 \\
\hline Do you know if your partner is an IDU? $(1-y e s / 0-n o)$ & 20.5 & 7.2 & 3.34 & $1.74-6.41$ & 0.0003 \\
\hline Do you accept IDU customers? $(1-$ yes $/ 0$-no) & 7.9 & 8.4 & 0.94 & $0.3-2.45$ & 0.9021 \\
\hline
\end{tabular}

${ }^{a} \exp (\beta)$, exponential of the corresponding coefficient in the univariate logistic regression. 
Table 3

Results of the multiple logistic regression stepwise procedure considering all drug related variables

\begin{tabular}{llll}
\hline Selected variables & Coefficient $(\beta)$ & $P$-value & Adjusted OR \\
\hline Did you smoke crack in the last month? (1-yes/0-no) & 1.79 & 0.0000 & 5.99 \\
Have you ever injected drugs? (1-yes/0-no) & 1.56 & 0.0031 & 4.78 \\
Do you know if your partner is an IDU? (1-yes/0-no) & 0.75 & 0.0448 & 2.13 \\
\hline
\end{tabular}

injected drugs?'. Of the 22 IDUs, ten $(45 \%)$ were HIV-infected $(\mathrm{OR}=11)$. The second most highly associated variable to the outcome was 'Did you use crack in the previous month?' Among crack users, the HIV infection rate (38\%) was six times the rate among non-users. Considerably weaker associations (although statistically significant at the $5 \%$ level) were found for the use of marijuana and snorted cocaine. Awareness that the regular partner was (or had been) an IDU was also relevant, with an OR of 3.3. However, the same did not apply to the variable 'Do you accept IDU customers?', since the corresponding OR was very close to 1 .

\subsection{Multivariate analyses}

The multivariate analysis of all drug-related variables emphasized the role of crack use, the first variable included in the stepwise model (Table 3). The other two relevant factors were related to drug use, with the probability of infection significantly greater for the CSWs who inject or have injected drugs and for those that were aware of having IDU regular partners. On the other hand, the partial effects relative to the use of snorted cocaine and marijuana were not significantly different from zero.

Results of the stepwise logistic regression procedure taking into account all independent variables are shown in Table 4. Among all considered variables, the use of crack in the previous month was the variable most highly associated to the outcome, with adjusted OR of 5.3. The use of injected drugs also showed a significant partial effect (adjusted OR $=3.1$ ). No other variable relative to drug use, when analyzed together with the others, was included in the model.
Interaction effects were also tested in the stepwise procedure, considering all possible two-bytwo combinations in the set of drug-related variables, but none of them showed statistical significance.

Given the relevant association between crack use and HIV infection among female CSWs found in this study, we concluded our analysis by considering a logistic regression model taking 'use of crack in the previous month' as the response variable. Results are shown in Table 5. Besides the simultaneous use of drugs via different routes, the findings indicate a significantly higher proportion of agreement to the question 'Do you agree not to use condoms if you need cash?', a significantly smaller payment per sexual encounter and a significantly lower age at first intercourse among crack users.

\section{Discussion}

Many studies have shown that crack use is associated with high levels of unprotected sex, which increases the heterosexual transmission of HIV (Des Jarlais et al., 1991) and other STDtransmission, such as syphilis (Rolfs et al., 1988; Fullilove and Fullilove, 1989). When strongly craving for a new dose and having no money to purchase the desired drug, crack users frequently engage in paid sexual intercourse without condoms and with multiple partners. Unprotected sexual intercourse is especially risky when partners are IDU, a population segment which often shows high HIV and other STD infection rates (Carvalho et al., 1996).

More recently, in a cohort of HIV-infected women, the relationship of crack use to STD 
incidence rates has been demonstrated. The role of crack use has been emphasized, referred to the possibilities of HIV re-infection, HIV-transmission to partners and two-way transmission of other STDs (DeHovitz et al., 1996). Other reported risks included is the possibility of HIV-oral transmission through sores in the oral mucosa (provoked by the crack pipe under high temperatures) (Inciardi, 1993).

In the city of Campinas, São Paulo, Manfrinatti et al. (1996) have found a considerably higher HIV infection rate among crack users compared to the rates found in general population surveys (such as pregnant women, blood donors and army conscript surveys) (Bastos et al., 1995). However, the specific association between crack use and HIV infection, as evidenced in this study, has never been demonstrated in Brazil.

As opposed to non-drug-using female CSWs, for whom systematic use of condoms is frequent in developed countries (European Working Group, 1993; Alary et al., 1994), drug using CSWs show lower frequency of condom use and often have more sexual encounters, probably as a consequence of the continuous cash demands to purchase drugs. These findings are confirmed in this paper. The analysis shows that crack-user CSWs agree more frequently to engage in unprotected sexual activity, start their sexual life at an earlier age, and earn, on average, a lower payment per sexual encounter than crack non-users.

Recently, Montoya and Atkinson (1996) have established that the HIV infection rate among IDUs is one of the key factors for high infection rates among non-IDUs living in the same locality. The idea is that the IDUs constitute a pool of infected individuals in continuous sexual interac- tion with the non-IDUs. Actually, the present investigation showed that crack users often use other illicit drugs. Furthermore, the analysis specifically indicated that crack users and IDU partners interact more frequently than crack non-users.

Despite the reduced number of IDU CSWs found in this study, it is worth noting the extremely high HIV infection rate $(45 \%)$ in this group of women, higher than the estimated rate in any other drug user group. This result is probably reflecting the considerable rise in the risk of HIV infection due to parenteral exposure.

The estimated HIV infection rate among IDUs in this study, though quite high, is considerably lower than the rate found by Carvalho et al. (1996) in an IDU sample in the city of Santos. Therefore, one may rightfully surmise that the sample of CSWs considered in this investigation probably excludes the women who are more affected by drug use, those more stigmatized and marginalized in society, refractory to the preventive activities carried out by the program. Further, this sample does not include HIV-infected women for whom the course of the disease (AIDS) seriously confines or hinders the exercise of their usual activities.

Several recent analyses, including those carried out by the authors of this paper (Szwarcwald et al., 1997; Bastos et al., 1998), point toward the 'impoverishment' of the AIDS epidemic in Brazil, that is, growing AIDS incidence rates in the lowincome population strata. One of the basic indicators of this process is the increasing number of AIDS cases with lower educational level, which takes particular relevance in a country like Brazil, characterized by a marked social heterogeneity.

Table 4

Results of the multiple logistic regression stepwise procedure taking into account all independent variables considered in the study

\begin{tabular}{|c|c|c|c|}
\hline Selected variables & Coefficient $(\beta)$ & $P$-value & $\exp (\beta)$ \\
\hline Did you smoke crack in the last month? (1-yes/0-no) & 1.66 & 0.0001 & 5.26 \\
\hline Educational level (1-illiterate/0-other) & 1.61 & 0.0003 & 4.98 \\
\hline Do you have anal intercourse with customers? (1-yes/0-no) & 1.03 & 0.0031 & 2.80 \\
\hline Have you ever injected drugs? (1-yes/0-no) & 1.14 & 0.0647 & 3.15 \\
\hline Age at first intercourse & -0.17 & 0.0188 & 0.85 \\
\hline
\end{tabular}


Table 5

Results of the multiple logistic regression stepwise procedure taking 'use of crack in the last month' as the response variable

\begin{tabular}{lcc}
\hline Selected variables & Coefficient $(\beta)$ & $P$-value \\
\hline Did you smoke cocaine in the last month? (1-yes/0-no) & 0.98 & 0.0193 \\
Age at first intercourse & -033 & 2.66 \\
Do you accept not to use condoms if you need cash? (1-yes/0-no) & 1.37 & 0.0005 \\
Did you use marijuana in the last month? (1-yes/0-no) & 1.01 & 0.0010 \\
Have you ever injected drugs? (1-yes/0-no) & 1.32 & 0.0153 \\
Do you know if your partner is an IDU? (1-yes/0-no) & 0.94 & 0.0530 \\
Cash amount for last sexual encounter & -0.03 & 0.0396 \\
\end{tabular}

Findings from this study confirm this. First, the HIV infection rate among illiterate CSWs is 4-fold the rate among those who have some schooling. Additionally, in the multivariate stepwise procedure, the variable 'educational level' was included in the final model, which indicates it is one of the most highly associated to the outcome. Similar findings have been reported by Lurie et al. (1995), who have also evidenced significantly higher HIV infection rates among CSWs with lower socioeconomic status.

Therefore, it seems that several variables relative to social and individual vulnerability sum up, in such a way that CSWs in the poorest strata and/or illicit drug users are certainly the most exposed group. Possible explanatory factors are: the role of drugs undermining cognitive skills and affecting the ability of negotiating safer sexual practices (Stall et al., 1986); deficient information and health service access among women with low living standards (Mann, 1995); the desperate need for cash among drug consumers (especially crack) which in turn contributes to riskier sexual practices.

The adverse social conditions in which those women live, especially the women that work on the streets, partially explain the higher levels of drug consumed by this population, even when compared to other populations under stressful working conditions in the city of Santos. For example, the truck driver survey has shown a lower drug consumption, although this group is under the specific risk of amphetamine-like stimulants ('rebite'), used when driving (Lacerda et al., 1996). Those unfriendly social conditions seem to be strongly related to risky sexual behaviors medi- ated by the harmful effects of crack cocaine, observed in the present sample and described in the international literature (Rolfs et al., 1988; Edlin et al., 1994).

Some limitations of this study have to be pointed out. First, by ethical requirements, only CSWs age 18 and over could be included in the current investigation. Therefore, it was not possible to characterize the group of professional sex workers under legal age, which would have included child prostitution as well. Former studies carried out in different Brazilian cities (although none of them specifically addressing Santos' 'scene') have indicated a great use of illicit drugs (including crack) by Brazilian street children (Noto et al., 1994), along with premature engagement in prostitution work. In a recent IDU multicenter study, involving 13 worldwide cities, the city of Santos has shown the highest HIV infection rate among 'new-injectors' (Friedman et al., 1998), emphasizing the urgent need to outline the drug new user profile in the city of Santos.

The second limitation of the study refers to the sampling procedure. Despite the attempt of the program (which spawned this investigation) to include a representative sample of CSWs, the selected sample is not a random sample of all CSWs living in Santos. As mentioned before, minor population segments may have been excluded in the analysis. So, although the conclusions of this study apply to a major group of adult CSWs, they cannot be generalized to the total population of female CSWs from Santos.

On the other hand, as several sampled CSWs were participating of the preventive program, some 'reporting bias' may also be found, regard- 
ing approval of the health professionals responsible for the program activities. Thus, unprotected sexual intercourse or the use of certain substances may be more frequent than reported, although recent papers have shown that drug users provide reliable information (Delrala et al., 1996) and the findings are in agreement with former qualitative results using focus group methods (Martins et al., 1996). In addition some questions, e.g. 'do you accept IDU customers?', involve subjective evaluation and cannot be considered as fully valid indicators.

Another limitation of the current investigation is the reduced number of users of some particular drugs found in the sample. Due to the statistical limitations resulting from small sample sizes, effects of simultaneous use of different drugs could not be analyzed.

Despite the body of limitations presented above, the association of HIV infection to crack and to use of injected drugs in this population is incontestable. Further, the majority of CSWs, whether HIV-infected or not, have already experimented with some kind of illicit drug. Taking into account that the transition to other drugs is relatively frequent throughout the course of drug-use (Strang et al., 1992; Des Jarlais et al., 1992), preventive programs should not only discourage general drug use but emphasize in particular the potentially higher HIV infection risk brought about by the transition to other drugs, specifically crack and injected powder cocaine.

The present study is inserted in a broad intervention program, which is already going on (Martins et al., 1996). The 52 sites currently assessed by the project are being visited weekly on a regular basis, focused on health education, through group sessions, video presentations followed by discussions and role-playing group dynamic, as well as condom distribution.

The specific question of drug consumption has been targeted by a harm reduction oriented program, implemented in 48 different sites with a high concentration of drug users (Gravato and Villarinho, 1998). Most of the sites overlap with the main street prostitution areas and have been visited by outreach workers on a daily basis. Since 1997, after a long period of legal controversies with the local law enforcement authorities, the activities of the outreach workers include the provision of sterile needle and syringes in exchange for used ones, in addition to the activities mentioned previously in the field of health education and promotion (Minayo et al., 1998).

\section{Acknowledgements}

This work was sponsored by the Brazilian Ministry of Health and Municipal Health Secretariat of Santos. CLS, FIB and EAC receive National Reasearch Council (CNPq) salary grants.

\section{References}

Alary M, Worm A-M, Kvinsdal B. Risk behaviors for HIV infection and sexually transmitted diseases among female sex workers from Copenhagen. International Journal of STD and AIDS 1994;5:365-7.

Bastos FI, Telles PR, Castilho EA, Barcellos C. The AIDS epidemic in Brazil. In: Minayo CS, editor. The Many Brazils: Public Health and Population in the 80s [Portuguese]. Sao Paulo/Rio de Janeiro: Hucitec and ABRASCO, 1995:245-68.

Bastos FI, Stimson G, Telles PR, Barcellos C. Cities responding to HIV-1 epidemics among injecting drug users. In: Stimson G, Des Jarlais DC, Ball A, editors. Drug Injecting and HIV Infection: Global Dimensions and Local Responses. London: UCL Press, 1998:149-67.

Bishop YMMS, Fienberg SE, Holland PW. Discrete Multivariate Analysis. Theory and Practice. Cambridge, MA: MIT Press, 1975.

Brazilian Ministry of Health. Epidemiological BulletinAIDS [Portuguese] 1997, X(4), Epidemiological Week-3648, September/November.

Bueno RC, Paes GL, Mesquita, FC, et al. A comparison of IVDU and heterosexual transmission in sex workers of low socioeconomic situation in Santos, Brazil. Proceedings of the Eighth International Conference on AIDS, Amsterdam, July 1992 [abstract PoC 4187].

Carvalho HB, Mesquita F, Massad E, et al. HIV and infections of similar transmission patterns in a drug injectors community of Santos, Brazil. Journal of Acquired Immune Deficiency Syndrome and Human Retrovirology 1996;12:84-92.

Caterino-de-Araújo A, Fortuna ED. Seropositivity to Chlamydia trachomatis in prostitutes: relationship to other sexually transmitted diseases. Brazilian Journal of Medical and Biological Research 1990;23:697-700.

DeHovitz JA, Wilson T, Feldman J, et al. STD incidence among seropositive women: the role of crack. Proceedings 
of the Eleventh International Conference on AIDS, Vancouver, July 1996 [abstract Tu.C 2484].

Delrala J, Bigelow C, McCusker J, Hindin R, Zheng L. Reliability of self-reported human immunodeficiency virus risk behaviors in a residential drug treatment population. American Journal of Epidemiology 1996;143:725-32.

Des Jarlais DC, Abdul-Quader A, Minkoff H, et al. Crack use and multiple AIDS risk behaviors. Journal of Acquired Immune Deficiency Syndromes 1991;4:446-7.

Des Jarlais DC, Casriel C, Friedman SR, Rosenblum A. AIDS and the transition to illicit drug injection-Results of a randomized trial prevention program. British Journal of Addiction 1992;87:493-8.

Edlin BR, Irwin KL, Faruque S, et al. Intersecting epidemics-Crack cocaine use and HIV infection among inner-city young adults. New England Journal of Medicine 1994;331:1422-7.

European Working Group on HIV Infections in Female Prostitutes. HIV infection in European female sex workers: epidemiological link with use of petroleum-based lubricants. AIDS 1993;7:401-8.

Friedman SR, Friedman P, Telles PR, et al. New injectors and HIV-1 risk. In: Stimson G, Des Jarlais DC, Ball A, editors. Drug Injecting and HIV Infection: Global Dimensions and Local Responses. London: UCL Press, 1998:76-90.

Fullilove MT, Fullilove RE. Intersecting epidemics. Black teen crack use and sexually transmitted diseases. Journal of the American Medical Women Association 1989;44:146-53.

Gravato N, Villarinho, LR. An experience on harm reduction in Santos. Proceedings of the Twelfth International Conference on AIDS, Geneva, July 1998 [abstract 33424].

Hosmer DW, Lemeshow S. Applied Logistic Regression. New York: Wiley, 1989.

Inciardi JA. Crack-cocaine in the Americas. In: Monteiro MG, Inciardi JA, editors. Brasil-United States Binational Research. Sao Paulo: CEBRID, 1993:63-76.

Kahn HA, Sempos CT. Statistical Methods in Epidemiology. New York: Oxford University Press, 1989.

Lacerda R, Stall R, Gravato N, et al. HIV infection and risk behaviors among male port workers in Santos, Brazil. American Journal of Public Health 1996;86:1158-60.

Lacerda R, Gravato N, McFarland W, et al. Truck drivers in Brazil: prevalence of HIV and other sexually transmitted diseases, risk behavior and potential for spread of infection. AIDS 1997;11:S15-9.

Lurie P, Femandes MEL, Hughes V, et al. Socioeconomic status and risk of HIV-1, syphilis and hepatitis B among sex workers in São Paulo State, Brazil. AIDS 1995;9:S317.

Manfrinatti MB, Silva JAG, Lima ES, Azevedo RCS. Epidemiology of HIV-1 among a sample of injecting drug users (IDU) and crack smokers (CS) in Campinas, Brazil. Proceedings of the Eleventh International Conference on AIDS, Vancouver, July 1996 [abstract Tu.C 2496].

Mann JM. Public health and human rights. Current Issues in Public Health 1995;1:97-101.

Martins D, Gravato N, Marcondes RC, et al. Qualitative assessment of a commercial sex worker intervention program in Santos, Brazil. Proceedings of the Eleventh International Conference on AIDS, Vancouver, July 1996 [abstract Th.D 5050].

Minayo MC, Deslandes SF, Souza ER, et al. Evaluation of the Brazilian harm-reduction projects [Portuguese]. FIOCRUZ/Brazilian Ministry of Health, Final Report.

Montoya ID, Atkinson JS. Determinants of HIV seroprevalence rates among sites participating in a community-based study of drug users. Journal of Acquired Immune Deficiency Syndrome and Human Retrovirology 1996;13:16976.

Noto AR, Nappo AS, Galduroz JCF, Mattei R, Carlini EA. III Survey on the Use of Drugs Among Street Boys and Girls in Five Brazilian Capitals, 1993 [Portuguese]. Sao Paulo: CEBRID/Escola Paulista de Medicina, 1994.

Porto AGM, Giraldes PRC, Marques RA, et al. Prevalence of HIV infections in pregnant women in the city of Santos [Portuguese]. RBM Ginecologia e Obstetrícia 1992;3:3047.

Porto AGM, Souza JAL Jr, Marra AR, et al. Risk factors among HIV-1-infected pregnant women living in different neighborhoods [Portuguese]. Revista Brasileira de Ginecologia e Obstetricía 1996;18:65-9.

Rolfs R, Goldberg M, Alexander ER, Sharrar R. Drug related behavior and syphilis in Philadelphia-sex for drugs. American Journal of Epidemiology 1988;128:898.

Stall R, McKusick J, Wiley J, et al. Alcohol and drug use during sexual activity and compliance with safe guidelines for AIDS: the AIDS Behavioral Research Project. Health Education Quarterly 1986;13:359-71.

Strang J, Des Jarlais DC, Griffiths P, Gossop M. The study of transitions in the route of drug use: The route from one route to another. British Journal of Addiction 1992;87:473-84.

Szwarcwald CL, Bastos FI, Andrade CLT, Castilho EA. AIDS: The ecological map of Brazil, 1982-1994 [Portuguese]. The AIDS Epidemic in Brazil: Situation and Trends. Brasília: Brazilian Ministry of Health, 1997:27-44.

Weniger BG, Limpakarjanarat K, Ungchusak K, et al. The epidemiology of HIV infection and AIDS in Thailand. AIDS 1991;5:S71-85.

Woodhouse DE, Rothenberg RB, Potterat JJ, et al. Mapping a social network of heterosexuals at high risk for HIV infection. AIDS 1994;8:1331-6. 